\title{
Inclusão - Revista da Educação Especial: um instrumento de comunicação pública e de defesa dos direitos humanos
}

\author{
Misiara Cristina Oliveira ${ }^{1}$
}

Maria Glaucia Magalhães ${ }^{2}$

\section{Resumo}

As transformações no paradigma dos direitos humanos na década de noventa, impulsionadas por uma cidadania planetária protagonista, composta por diferentes sujeitos de direitos, os quais se mobilizam em direção à defesa de direitos específicos como integrantes de uma plataforma universal, influenciam as políticas públicas dos diferentes Estados-Nação e em especial do Brasil. Como decorrência desse referencial ético mais global, as políticas de comunicação e educação passam a ser trabalhadas como direitos fundamentais contextualizadas nesta abordagem contemporânea de direitos humanos. Assim, são desenvolvidos os conceitos mais atuais de comunicação pública e de inclusão educacional: comunicação pública como promotora do interesse público e dos direitos de cidadania e inclusão educacional como política e prática pedagógica que promove o acesso, a participação e a aprendizagem de todos os alunos nos espaços comuns da escola, em convívio com os demais de sua geração.

Palavras-chave: Direitos humanos. Igualdade. Diferença. Comunicação. Comunicação pública.Inclusão educacional.

\section{Introdução}

Este artigo teve como origem a monografia de conclusão do curso de Comunicação Social, apresentada no final do primeiro semestre de 2009, no Centro

\footnotetext{
${ }^{1}$ Autora graduada em Comunicação Social pelo Centro Universitário de Brasília - UniCEUB. E-mail: misiaraoliveira@gmail.com.

${ }^{2}$ Coautora Orientadora. Graduada em Comunicação Social. Especialização em Educação, Marketing e Gestão Empresarial.
} 
Universitário de Brasília (UniCEUB), a qual desenvolveu um estudo sobre a revista publicada pela Secretaria de Educação Especial do Ministério da Educação, Inclusão - Revista da Educação Especial.

A monografia partiu da contextualização dos processos de redefinição conceitual na área dos direitos humanos e da comunicação pública, resultante da organização e mobilização dos diferentes movimentos sociais que lutam pelo reconhecimento e visibilidade de suas especificidades. Essas lutas geraram conquistas que repercutem na elaboração das políticas públicas dos diferentes Estados - Nação pelo mundo.

Neste contexto, dois marcos são significativos. O primeiro é a Declaração Mundial de Direitos Humanos e o Programa de Ação de Viena de 1993 que, pela primeira vez, apresenta o direito à diferença ao lado do direito à igualdade e declara que os direitos específicos compõem a universalidade dos direitos humanos. Já o segundo marco, voltado à área da comunicação, provém das elaborações do teórico francês Pierre Zémor, que a partir de 1995 passa a desenvolver uma nova concepção de comunicação pública,que serve de referência às linhas de pesquisa e às políticas públicas em todo o mundo.

Dessa forma, o estudo buscou relacionar esses dois marcos conceituais, a fim de contribuir com os debates e desenvolvimento de estudos nas áreas da comunicação, das políticas públicas e dos direitos humanos.

Nesta perspectiva, a monografia desenvolveu um estudo da Inclusão - Revista da Educação Especial, por meio da análise de dois objetos: a comunicação pública e os direitos humanos, a fim de verificar se a Revista Inclusão se constitui em um veículo que se utiliza da forma e da estratégia de comunicação pública e se o seu conteúdo promove e defende os direitos humanos, e em qual perspectiva.

A metodologia utilizada foi a pesquisa qualitativa e exploratória, utilizando como técnica a pesquisa bibliográfica sobre os conceitos mais recentes de comunicação pública e de abordagens teóricas mais atuais sobre os direitos humanos; a pesquisa documental sobre os marcos políticos e legais dos direitos humanos e da inclusão educacional, e a de campo, por meio de entrevistas com representantes dos segmentos de defesa dos direitos das pessoas com deficiência, com professores dos sistemas públicos de ensino, com gestores de educação especial, com pesquisadores e com especialistas no tema educação inclusiva no Brasil. 
Para análise da revista, foi escolhida a de conteúdo. Foram analisadas seis edições, divididas em seções, artigos e matérias de destaque, publicadas no período de 2005 a 2008. Além disso, o estudo procurou entender sobre a estratégia de comunicação utilizada pela Secretaria de Educação Especial para divulgação e efetivação da política pública de inclusão educacional.

\section{Desenvolvimento}

A articulação entre temas fundamentais para a análise do conteúdo e da forma que estruturam a mídia estudada possibilitou o aprofundamento dos conceitos de comunicação, comunicação pública e direitos humanos, constituindo uma rede com pontos de encontro entre essas elaborações.

A opção teórica escolhida para o desenvolvimento da monografia foi a de tomar como referência as definições que têm sido mais utilizadas no Brasil, tanto nos espaços acadêmicos como nas esferas governamentais responsáveis pela implementação de políticas públicas que destacam o protagonismo dos cidadãos nos processos de construção dessas ações.

As bases das formulações contemporâneas sobre a comunicação pública no Brasil estão estruturadas a partir da elaboração do teórico francês Pierre Zémor (1995), que define o domínio da comunicação pública pela legitimidade do interesse geral que ultrapassa o domínio público e que se situa necessariamente no espaço público.

Dessa forma, o autor parte para a descrição do propósito dessa comunicação que está estritamente relacionado com as finalidades das instituições públicas, estabelecidas em um regime democrático, o qual leva em conta as relações sociais entre cidadãos e os órgãos ou instituições que se propõem a realizar uma comunicação de interesse público.

Assim, a comunicação pública passa a cumprir um papel estratégico para a formulação e implementação das políticas públicas, pois serve de instrumento de disseminação de conhecimentos e informações, de estímulo ao debate sobre os temas de interesse público e fundamentalmente de mobilização social. "Espera-se da Comunicação Pública que sua prática contribua para alimentar o conhecimento cívico, facilitar a ação pública e garantir o debate público” (ZÉMOR, 1995, p. 1). 
Enquanto política de governo, a comunicação pública cumpre um papel de garantir a transparência e o acesso aos atos governamentais para toda a sociedade, por meio da disseminação de informações e de estímulos a uma participação mais efetiva da população nas ações e atividades propostas pelas demais políticas públicas.

A marca dos governos democráticos tem sido o compromisso com os direitos de cidadania e com a implementação de ações comunicativas que, além de informar, estimulam o protagonismo. A comunicação pública, nesse cenário, é um elemento de mobilização social, tendo por objetivo atender as demandas comunicacionais e de informação decorrentes da sociedade e instrumentalizar esta sociedade para as ações.

Para Brandão (2007, p. 9), especialmente pelo esforço da área acadêmica, o ponto comum no entendimento do conceito de comunicação pública no Brasil irá referir-se ao processo comunicativo que se instaura entre o Estado, o governo e a sociedade com o objetivo de informar para a construção da cidadania.

Nesse sentido, quanto mais democrático for o Estado ou o governo, mais intensa será esta construção da participação social, mais presente no dia a dia da sociedade serão os direitos de cidadania, mais plurais serão as mensagens, mais numerosos e diversificados serão os meios que se constituem como espaço público ou esfera pública. Dessa forma, será mais efetivo todo o processo comunicativo, pois ele estará validado por meio da interlocução com esses agentes sociais.

Pode-se ainda referir que a comunicação pública vai se afirmando como um instrumento estratégico nos processos de garantia e efetivação de direitos, de fortalecimento da cidadania e de desenvolvimento humano e social.

É nesse ponto que a comunicação pública estabelece um diálogo fundamental com os direitos humanos e as políticas de inclusão, pois ela só pode ser concretizada neste cenário de uma sociedade protagonista que promove e garante os direitos de todos. 


\subsection{Direitos Humanos}

No marco dos 60 anos da Declaração Universal dos Direitos Humanos, completados em 2008, o estudo apresentou elementos que compõem o debate atual acerca das definições contemporâneas de direitos humanos, que têm evoluído no transcorrer da história, por meio das mobilizações e lutas de diferentes movimentos e segmentos sociais organizados. Para Hannah Arendt (apud PIOVESAN, 2004, p. 46), os direitos humanos não são um dado, mas um construído, uma invenção humana em constante processo de construção e reconstrução.

Nesse contexto, os movimentos sociais do final dos anos oitenta e do início da década de noventa, com destaque especial para os movimentos feministas, influenciaram novas abordagens teóricas sobre os direitos humanos e conquistaram definições significativas a partir da Convenção de Direitos Humanos de Viena de 1993, que atualizou e ampliou o sentido proposto pela Declaração Universal de Direitos Humanos de 1948.

As questões centrais apresentadas desde a Declaração de 1948 são a universalidade e a indivisibilidade desses direitos, que têm sido defendidas e exercitadas por militantes da luta em prol dos direitos humanos de todo o mundo, como princípios fundamentais que não devem ser flexibilizados.

Esses princípios fundamentais foram mantidos em Viena, como um eixo estruturante desse arcabouço político normativo, acrescido de uma formulação que visa superar o paradigma da homogeneidade sem, no entanto, permitir que as particularidades locais, regionais, sociais ou culturais se sobreponham aos direitos fundamentais ou justifiquem suas violações.

Essas abordagens buscam superar a visão universalista de direitos, baseada em um paradigma homogêneo de humanidade e introduzem o tema do direito à diferença, à expressão da diversidade e das especificidades de cada sujeito de direito. A Convenção de Viena, segundo Trindade (apud PIOVESAN, 2004, p. 63), compreende finalmente que a universalidade é enriquecida pela diversidade cultural, que jamais pode ser invocada para justificar a denegação ou violação dos direitos humanos.

A partir dessa última definição, serão desenhadas abordagens conceituais no sentido de dar conta das questões prementes para os direitos humanos con- 
temporâneos. Dentre essas questões, está a articulação entre o direito à igualdade e o direito à diferença, que surge como alternativa para a falsa dicotomia entre universalismo de direitos e o relativismo cultural. Dentre os principais teóricos que irão debruçar-se sobre esse desafio, destaca-se o sociólogo português Boaventura Souza Santos, o qual passa a ter grande influência nesse debate no Brasil, junto a correntes teóricas, políticas e movimentos sociais envolvidos com a temática dos direitos humanos.

O multiculturalismo progressista pressupõe que o princípio da igualdade seja prosseguido de par com o princípio do reconhecimento da diferença. [...] pressupõe a aceitação do seguinte imperativo transcultural: temos o direito a ser iguais quando a diferença nos inferioriza; temos o direito de ser diferentes quando a igualdade nos descaracteriza (SANTOS, 2008, p. 462).

Essa influência pode ser constatada na produção de vários expoentes na área no Brasil que, a partir dessa elaboração, aprofundam essas questões introduzindo outros temas como o da desigualdade, gerando um novo marco conceitual para os direitos humanos no país.

No avanço das formulações, os principais teóricos brasileiros optam por uma abordagem sobre uma universalidade de direitos composta pela diversidade e pluralidade, em que o reconhecimento e a valorização das diferenças passam a ser um componente fundamental para a defesa, a promoção e a garantia dos direitos humanos.

A efetiva proteção dos direitos humanos demanda não apenas políticas universalistas, mas específicas, endereçadas a grupos socialmente vulneráveis, enquanto vítimas preferenciais da exclusão. Isto é, a implementação dos direitos humanos requer a universalidade e a indivisibilidade destes direitos, acrescidas do valor da diversidade (PIOVESAN, 2008, p. 238).

Nesse contexto, fortalecem-se no Brasil as concepções voltadas para a defesa da existência de diferentes e legítimos sujeitos de direitos que devem ter suas especificidades reconhecidas e valorizadas no marco da defesa de uma universalidade de direitos, composta pelo plural e heterogêneo. Essa visão fica mais explícita ao defender o direito de todos terem seus direitos específicos garantidos. 
Ao aprofundar o debate sobre igualdade e diferença, surgem as questões referentes às desigualdades sociais geradoras de exclusão social, que passam a ser enfrentadas de outra forma, não aceitando mais que sejam justificadas pelas diferenças culturais, físicas, sexuais e religiosas, dentre outras.

Esse processo desenvolve-se em consonância com a abordagem dos direitos humanos inspirada nos marcos do multiculturalismo proposto por Santos (2008), um multiculturalismo progressista que não se abstém da defesa de valores universais, desde que eles estejam conjugados com a diversidade e a diferença. Esse movimento conceitual se reflete nas diferentes áreas de conhecimento, influenciando de forma direta as políticas públicas, que passam a exigir de seus gestores e profissionais posturas e ações concretas de reconhecimento e valorização da diversidade.

Nesse contexto, fortalece-se uma visão estratégica para a educação como espaço privilegiado para a socialização, para a interação e para a construção dos sujeitos, sujeitos de direitos e de direitos humanos.

\subsection{Inclusão}

Assim, a construção de uma sociedade inclusiva pressupõe o reconhecimento e a valorização das diferenças, o exercício pleno dos direitos humanos pelos sujeitos de direitos, a incorporação no cotidiano dos conceitos, dos marcos legais e desse novo paradigma social que tem sido construído nos últimos anos. Para Vivarta (2003), o conceito de inclusão é uma conquista no campo dos direitos humanos modernos, em plano nacional e internacional, com o objetivo de dignificar toda a diversidade humana. Inclusão é o direito de todos os seres humanos participarem ativamente da vida pública, sem limites de credo, religião, posição política, etnia, opção sexual ou grau de deficiência.

O conceito de sociedade inclusiva está baseado em princípios simples, mas orientadores da afirmação e defesa dos direitos humanos, como bem destacou Werneck (2002, p. 188): “A sociedade inclusiva baseia-se em um princípio elementar: todas as pessoas têm o mesmo valor". 


\subsection{Educação inclusiva}

A educação inclusiva rompe com padrões tradicionais que constituíram uma visão de educação e de escola referenciados na homogeneidade, no mérito, na seletividade que influenciaram a constituição de organizações e estruturas verticalizadas, excludentes e, em muitos casos, segregadas, como é a experiência das escolas especiais.

Esse novo paradigma educacional tem marcado as políticas públicas nesta última década, impulsionando a transformação dos sistemas educacionais brasileiros em sistemas educacionais inclusivos que garantam, além do acesso pleno de todos à educação, condições de participação e aprendizagem.

Relacionando as contribuições desses autores, percebe-se um avanço no sentido do reconhecimento das diferenças, do reconhecimento que o todo humano é plural e diverso e que cada indivíduo possui especificidades; e esse deve ser o principal componente comum, universal a toda humanidade. A sociedade inclusiva é a sociedade democrática concebida em sua pluralidade, que possibilita que todos os seres humanos possam usufruir e interagir com o todo desta sociedade.

A educação, nesse aspecto, apresenta-se como política pública estratégica para a afirmação desses valores junto à sociedade e para um efetivo desenvolvimento humano e social de toda a humanidade.

Os direitos humanos são os valores, os princípios e os fundamentos. São os marcos que compõem o referencial ético de uma sociedade. Já a inclusão trata da forma e da atitude como esses valores devem ser vivenciados e exercidos. Juntos, direitos humanos e inclusão, traduzem-se no conteúdo primordial a ser disseminado por qualquer política pública que se proponha a ser efetivamente construtora de cidadania.

A comunicação pública, nesse contexto, constitui-se como um meio estratégico para a concretização dessas políticas públicas, pois é elemento de coesão e enraizamento na sociedade desses valores e formas de ação. Isso ocorre por meio da disseminação de informações, da mobilização social, do estímulo ao debate e ao protagonismo e por meio de processos educativos e formativos voltados para uma vivência cidadã em sociedade. Assim, a comunicação pública passa a ser um instrumento para o empoderamento da população com relação às políticas públicas, consolidando dessa forma a experiência democrática. 
A essência da comunicação pública é a de estar intimamente comprometida com a defesa dos direitos humanos e da inclusão, pois sua existência pressupõe a efetivação do direito à informação e à comunicação, o reconhecimento dos sujeitos de direitos, a valorização das diferenças no marco da universalidade dos direitos fundamentais, a pluralidade e a democracia.

\subsection{Inclusão - Revista da Educação Especial}

A Inclusão - Revista da Educação Especial teve sua primeira edição publicada em outubro de 2005 e já em seu primeiro editorial apresentou seu principal objetivo que era o

de ampliar e disseminar conhecimentos técnicos e científicos, estimular o intercâmbio de experiências entre os diversos profissionais que atuam no processo de inclusão educacional e atendimento às necessidades educacionais especiais dos alunos.

A Revista está estruturada em oito seções: Editorial, Entrevista, Destaque, Enfoque, Resenhas, Informes, Veja Também e Opinião. No decorrer das seis edições, houve alterações nesse formato, como a edição especial de 2008, que apresentou a Política Nacional de Educação Especial na Perspectiva da Educação Inclusiva. Nessa edição, foi inserida uma seção denominada Colóquio e foram retiradas as seções Resenhas e Veja Também. Essa edição especial teve uma tiragem diferenciada de 100 mil exemplares.

A tiragem da revista tem evoluído desde suas primeiras três edições, que foi de 40 mil exemplares, passando para 50 mil exemplares nas edições quatro e seis e para 100 mil exemplares a partir das edições sete e oito previstas para 2009. Houve ainda em abril de 2008, uma segunda edição com tiragem de 15 mil exemplares das edições de um a três.

Desde sua primeira edição, a revista foi indexada em Bibliografia Brasileira de Educação (BBE)/Instituto Nacional Anísio Teixeira (INEP) e, em 2008, a partir da quinta edição, passou a ser indexada também em Latindex - Sistema Regional de Información em Línea para Revistas Científicas de America Latina, EI Caribe, Espana y Portugal. 
Um dos diferenciais da Revista Inclusão é a coerência da linha editorial com o formato apresentado. Todas as edições têm seus exemplares acompanhados de CDs, que contêm o conteúdo da revista em formato PDF. Nas edições no 5 e 6 , além do PDF, foi disponibilizado o formato TXT. Na capa de cada CD há a descrição do laybol em Braille.

Todas as edições estão disponíveis nos formatos PDF e TXT no sítio do Ministério da Educação, como forma de garantir o acesso a todos que desejarem, ampliando em muito as possibilidades de difusão e disseminação desse veículo.

Por meio da garantia da acessibilidade, a revista se torna um instrumento de inclusão não só pelo conteúdo, mas também pela forma como chega ao seu público leitor.

Segundo informações da Secretaria de Educação Especial, do Ministério da Educação, no que se refere ao relacionamento da revista com seu público leitor, há um e-mail institucional com uma média de 10 mensagens diárias recebidas, nas quais os leitores sugerem temas e pautas, encaminham artigos, solicitam cadastro para recebimento da revista e exemplares de edições antigas, pedem informações sobre as ações da Secretaria e outros materiais pedagógicos da área.

Em dezembro de 2007, foi realizada uma enquete pela Secretaria de Educação Especial, com uma amostra de 1.261 leitores, para dimensionar a abrangência da leitura da revista e o perfil dos leitores. Nessa verificação, constatou-se que, desse total, 90,6\% eram mulheres e 9,4\% eram homens e que a revista possuía uma média de 6,1 leitores por exemplar. Quanto à formação dos leitores, 42,8\% têm curso superior, $37 \%$ têm pós-graduação e 13,6\% possuem curso médio de magistério.

\subsection{Análise da revista quanto às estratégias de comunicação}

A relação da Revista com seu público leitor se dá prioritariamente pelo seu e-mail institucional - revistainclusao@mec.gov.br, por correspondências encaminhadas pelo correio, eventualmente pelo e-mail institucional da Secretaria de Educação Especial do Ministério da Educação - seesp@mec.gov.br, ou por telefone.

Por meio desses canais, o público encaminha sugestões de pauta, relatos de experiências educacionais inclusivas, resenhas e artigos científicos voltados à área 
de educação especial, à temática da inclusão educacional e dos direitos humanos, além da solicitação de exemplares da revista.

Desta forma, é estabelecido um espaço de interação, no qual o público participa indiretamente das definições editoriais e de conteúdo. Essas contribuições são submetidas a duas esferas de decisão: a Comissão Organizadora e o Conselho Editorial.

Nesse contexto, Matos (2007) afirma que essas esferas de participação e deliberação são os espaços físicos e imateriais que se constituem como esfera pública, onde é efetivada a participação social.

Além da distribuição, há espaço para o público leitor solicitar o cadastro para recebimento da revista diretamente em sua escola ou residência. A revista ainda fica disponível na página da internet do Ministério da Educação, nos formatos PDF e TXT, para que possa ser acessada por qualquer pessoa.

A divulgação da revista e desses canais de acesso e participação se dá no próprio corpo da revista, na página do Ministério da Educação na internet e em eventos promovidos pelo MEC e pela Secretaria de Educação Especial.

Por meio das entrevistas e da pesquisa documental, foi verificado que a Inclusão - Revista da Educação Especial - é o elemento estruturante da estratégia de comunicação governamental e pública adotada pela Secretaria de Educação Especial do Ministério da Educação.

Dentre as características constatadas, está a preocupação de um diálogo qualificado com seu público leitor, com profissionais e com pesquisadores que atuam na área por meio da constituição de canais concretos de participação, da formalização de opiniões sobre os temas e o conteúdo editorial da publicação, efetivando o direito à comunicação para esse público, por meio do acesso e do poder de comunicar, conforme referido por Peruzzo (2004).

Outra característica importante é a abertura da revista para o contraponto em relação à linha editorial. Nesse aspecto, a edição no 5 se sobressai ao trazer a pluralidade de opiniões acerca da Política Nacional da Educação Especial na Perspectiva da Educação Inclusiva. 
Desse modo, são estabelecidas relações com os diferentes segmentos que atuam na área por meio de uma articulação com as demais políticas públicas relacionadas com o tema, visando o interesse coletivo por meio da defesa dos direitos de cidadania dos diferentes sujeitos.

Nesse aspecto, a revista cumpre as funções da Comunicação Pública propostas por Zémor (1995) ao informar, ouvir as demandas, as interrogações e o debate público, contribuir para assegurar a relação social e acompanhar as mudanças, tanto as comportamentais quanto as da organização social.

Nesse contexto, destacam-se duas seções que propõem um diálogo direto com o público leitor - a seção Opinião, que possibilita a expressão de posicionamentos acerca dos temas abordados pela revista e a seção Veja Também, que abre espaço para o relato de experiências educacionais inclusivas.

As ações da revista visam dar conhecimento dos direitos de cidadania às pessoas com deficiência e ao público da educação especial, priorizando o debate sobre o tema e estimulando a participação do público leitor nas definições da revista, mesmo que de forma indireta.

Apesar de todas essas características, ainda devem ser aprofundadas as formas e ampliados os espaços para a participação da sociedade nas decisões acerca da comunicação desenvolvida, a fim de que essa participação passe a ter uma influência mais direta nessas decisões.

\subsection{Análise da revista quanto ao conteúdo}

Ao analisar as seis edições da revista, constatou-se que de um total de cinquenta e sete textos, excluídos os das seções Resenhas e Informes, no que se refere à abordagem explícita, os direitos humanos são apresentados em nove elaborações. O conceito de diversidade, da mesma forma, é discutido de forma direta em nove textos. A valorização das diferenças e o direito à diferença aparecem de forma direta em treze textos. Os direitos das pessoas com deficiência aparecem diretamente em seis textos. Dessa forma, trinta e sete textos apresentam de forma direta uma abordagem contemporânea de direitos humanos, além disso, o tema da inclusão educacional está presente de forma direta em todos os textos. 
As demais elaborações apresentam esses conceitos, princípios e fundamentos dos direitos humanos contemporâneos, fundamentados nos princípios da diversidade e da articulação entre os direitos à igualdade e à diferença de forma indireta, discutindo os diferentes aspectos e especificidades relacionados a essas temáticas.

Desse modo, identifica-se claramente que são trabalhados nos textos das seis edições os aspectos significativos da universalidade e a indivisibilidade dos direitos humanos, o reconhecimento e a valorização da diversidade e das diferenças sem que elas possam justificar atos discriminatórios, ou demais violações de direitos.

O eixo temático principal abordado em todas as edições é o do direito de todos à educação, compreendido como um direito humano essencial, e como um meio fundamental para acessar e exercer outros direitos. Assim, o direito de todos à educação é concebido a partir dos conceitos de sociedade inclusiva e de educação inclusiva, voltados ao reconhecimento, acolhimento e valorização de todos.

Tendo como referência Piovesan (2008), pode-se situar a linha editorial do direito de todos à educação como uma política universalista, que exige estar acompanhada de políticas específicas como a oferta do atendimento educacional especializado e a promoção das condições de acessibilidade, a fim de dar respostas às demandas das pessoas com deficiência e do público da educação especial no sistema educacional. Esses segmentos constituíram-se, ao longo da história, como grupos socialmente vulneráveis, vítimas preferenciais da exclusão, da discriminação, da segregação e da negação à efetiva participação e pertencimento aos espaços comuns da sociedade.

Assim, a inclusão é uma expressão do ideal dos direitos humanos, ao pressupor, como referiu Vivarta (2003), o direito de todos os seres humanos participarem ativamente da vida pública. No caso do público da educação especial, isso pode ser traduzido como o direito de participar ativamente da escola e dos processos educacionais, por meio do acesso, da participação e da aprendizagem em conjunto com os demais alunos. 
Todos os textos presentes nas diferentes edições da revista partem de um pressuposto fundamental de que a condição de pessoa é o requisito único para a dignidade e titularidade de direitos, atribuindo a todos os seres humanos o mesmo valor.

Nesse contexto, tendo como referência Piovesan (2008), a educação inclusiva, preconizada pela linha editorial da revista, está situada na vertente que trabalha a concepção de igualdade material como correspondente ao ideal de justiça enquanto reconhecimento das identidades. É, portanto, a efetiva articulação entre o direito à igualdade e o direito à diferença, com suas mediações necessárias para que não sirvam de instrumento de violação de direitos.

A partir da pesquisa documental, das entrevistas e da análise das seis edições da revista, pode-se afirmar que a linha editorial é desenvolvida no sentido de uma ação não de governo, mas de Estado, comprometida com valores e princípios básicos de defesa, promoção e garantia dos direitos humanos, em especial dos direitos humanos das pessoas com deficiência, tendo como foco principal o direito de todos à educação.

Assim, a Revista, pelo seu conteúdo, propõe-se a promover o debate e a mobilização social, estimulando o protagonismo em torno de uma política pública educacional inclusiva que rompe com uma visão homogeneizadora de escola, de sociedade e de humanidade, passando a reconhecer e valorizar as diferenças presentes nos diferentes contextos sociais e em especial nas escolas.

Por meio da educação inclusiva se fortalece o papel da educação como espaço privilegiado de construção de sujeitos de direitos, por meio de sua contextualização social e cultural, do estímulo ao seu protagonismo, apresentando, dessa forma, uma nova abordagem sobre a educação que, de acordo com Carbonari (2007), deve ser cumpridora de uma exigência ética de promover a construção de atitudes e posturas de vida.

\section{Conclusão}

O trabalho monográfico foi desenvolvido a partir da definição dos objetivos de se realizar um estudo de caso por meio da análise sobre a estratégia de comunicação desenvolvida pela Secretaria de Educação Especial do Ministério da Edu- 
cação, por meio da publicação intitulada Inclusão - Revista da Educação Especial, bem como da análise de conteúdo da revista.

A primeira parte foi dedicada à pesquisa bibliográfica e documental dos temas, comunicação pública, direitos humanos, direitos das pessoas com deficiência e inclusão educacional, constituindo o referencial teórico de base para as análises propostas.

$\mathrm{Na}$ segunda etapa, foi priorizada a pesquisa documental, tendo como foco a própria revista e as informações disponibilizadas pela Secretaria de Educação Especial, seguida da elaboração e concessão de entrevistas pela gestora, pesquisadoras da área, jornalista e professora do sistema público de ensino, a fim de subsidiar a apresentação do referido veículo e a própria análise dos dois objetos.

$\mathrm{Na}$ terceira fase, a aluna realizou a análise da revista com base no referencial teórico, buscando contextualizá-la quanto aos conceitos contemporâneos de comunicação pública e de direitos humanos.

Durante a análise, constatou-se que a Inclusão - Revista da Educação Especial desenvolve estratégias de comunicação muito próximas dos objetivos e finalidades da comunicação pública, ao servir de elemento de mobilização social, de estímulo à participação do público no debate e na formulação das políticas públicas, de constituição de espaços públicos para essa participação, de ouvir as demandas desse público e de defender e garantir o interesse público.

No que se refere à análise de conteúdo,, a linha editorial deixa claro o compromisso com a defesa da inclusão educacional, contextualizada e fundamentada a partir dos referenciais éticos e de uma concepção atual dos direitos humanos, a qual conjuga as questões da igualdade, da diferença e da diversidade dos sujeitos de direitos e das especificidades e da universalidade dos direitos.

Por fim, pode-se afirmar que a Inclusão - Revista da Educação Especial tem percorrido um caminho promissor no sentido de efetivar o direito à comunicação, por meio de estratégias de comunicação que contemplem aspectos das formas de comunicação governamental, estatal e pública, pois, tendo como referência Brandão (2007), ela cumpre o papel de ser um instrumento de construção da agenda pública, de estímulo para o engajamento da população nas políticas adotadas, provocando o debate público e garantindo o interesse público. 


\section{Inclusão - Revista da Educação Especial: an instrument of public communication and protection of human rights}

\section{Abstract}

Transformations on human rights paradigm ocurred in the nineties, driven by a worldwide protagonist citizenship, composed of different subjects of rights, who are mobilizing to defend specific rights as members of a universal platform, influencing the public policies of different States and especially Brazil. As a result from global etical references, the communication policies and education start to be worked as fundamental rights in this contextualized contemporary approach of human rights. Thus are developed the newest concept of public communication and and educational inclusion. Public Communication as a promoter of public interests and the rights of citizenship and educational inclusion as the educational policy and pedagogical experience, that promotes access, participation and learning for all students in common areas of the school, living together with others of their generation.

Keywords: Human rights. Equality. Differences. Communication. Public Communication. Educational Inclusion.

\section{Referências}

BALDI, César Augusto (Org.). Direitos humanos na sociedade cosmopolita. Rio de Janeiro: Renovar, 2004.

BRANDÃO, Elizabeth Pazito. Conceito de comunicação pública. In: DUARTE, Jorge. Comunicação pública: estado, mercado, sociedade e interesse público. São Paulo: Atlas, 2007.

BRASIL. Comitê Nacional de Educação em Direitos Humanos Secretaria Especial dos Direitos Humanos. Plano Nacional de Educação em Direitos Humanos. Brasília, 2008.

BRASIL. Presidência da República. Secretaria Especial dos Direitos Humanos. Revista Direitos Humanos, Brasília, dez. 2008.

BRASIL. Presidência da República. Secretaria Especial dos Direitos Humanos. Convenção sobre os direitos das pessoas com deficiência. Brasília, set. 2007. 
BRASIL. Presidência da República. Decreto n 6.751, de 17 de março de 2008. Dispõe sobre o atendimento educacional especializado, regulamenta o parágrafo único do art.60 da Lei n. 9.394, de 20 de dezembro de 1996, e acrescenta dispositivo ao Decreto n. 6.253, de 13 de novembro de 2007. Diário Oficial da União, Brasília, $n^{\circ} 188,18$ set. 2008 . Seção 1. p.26.

INCLUSÃO: REVISTA DA EDUCAÇÃO ESPECIAL. Brasília: Ministério da Educação; Secretaria de Educação Especial, n. 1, 2005.

INCLUSÃO: REVISTA DA EDUCAÇÃO ESPECIAL. Brasília: Ministério da Educação; Secretaria de Educação Especial, n. 2, 2006.

INCLUSÃO: REVISTA DA EDUCAÇÃO ESPECIAL. Brasília: Ministério da Educação; Secretaria de Educação Especial, n. 3, 2006.

INCLUSÃO: REVISTA DA EDUCAÇÃO ESPECIAL. Brasília: Ministério da Educação; Secretaria de Educação Especial, n. 4, 2007.

INCLUSÃO: REVISTA DA EDUCAÇÃO ESPECIAL. Brasília: Ministério da Educação; Secretaria de Educação Especial, v. 4, n. 1, 2008.

INCLUSÃO: REVISTA DA EDUCAÇÃO ESPECIAL. Brasília: Ministério da Educação; Secretaria de Educação Especial, v. 4, n. 2, 2008.

CARBONARI, Paulo César. Sujeito de direitos humanos. In: SILVEIRA, Rosa Maria Godoy (Org.). Educação em direitos humanos: fundamentos teóricometodológicos. João Pessoa: Universitária, 2007.

DUARTE, Jorge (Org.). Comunicação pública: estado, mercado, sociedade e interesse público. São Paulo: Atlas, 2007.

MANTOAN, Maria Teresa Eglér (Org.). O desafio das diferenças nas escolas. Petrópolis, RJ: Vozes, 2008.

MARTINS, José Renato Vieira et al. (Org.). Educação para a paz e direitos humanos. Brasília: Presidência da República, 2008.

MATOS, Heloiza. Comunicação pública, esfera pública e capital social. In: DUARTE, Jorge: Comunicação pública: estado, mercado, sociedade e interesse público. São Paulo: Atlas, 2007.

MONTEIRO, Graça França. A singularidade da comunicação pública. In: 
DUARTE, Jorge. Comunicação pública: estado, mercado, sociedade e interesse público. São Paulo: Atlas, 2007.

OLIVEIRA, Maria José da Costa (Org.). Comunicação pública. Campinas: Alínea, 2004.

PAULA, Ana Rita de; Izabel Maria de Loureiro Maior. Um mundo de todos para todos: universalização de direitos e direito à diferença. Revista Direitos Humanos, Brasília, p.36-37, 2008.

PERUZZO, Cicília M. Krohling. Direito à comunicação comunitária, participação popular e cidadania. In: OLIVEIRA, Maria José da Costa: Comunicação pública. Campinas: Alínea, 2004.

PIOVESAN, Flávia. A universalidade e a indivisibilidade dos direitos humanos: desafios e perspectivas. In: BALDI, César Augusto (Org.). Direitos humanos na sociedade cosmopolita. Rio de Janeiro: Renovar, 2004.

PIOVESAN, Flávia. Direitos humanos: desafios da ordem internacional contemporânea. In: MARTINS. José Renato Vieira et al. (Org.). Educação para a paz e direitos humanos. Brasília: Presidência da República, 2008.

SILVEIRA, Rosa Maria Godoy et al. (Org.). Educação em direitos humanos: fundamentos teórico-metodológicos. João Pessoa: Universitária, 2007.

DECLARAÇÃO E PROGRAMA DE AÇÃO DE VIENA. Viena, 1993. Disponível em: <http://www.dhnet.org.br/direitos/anthist/viena/declaracao_ viena.htm> Acesso em: 28 de mar. 2009.

SANTOS, Boaventura Souza. Por uma concepção multicultural dos direitos humanos. In: BALDI, César Augusto (Org.). Direitos humanos na sociedade cosmopolita. Rio de Janeiro: Renovar, 2004.

SANTOS, Boaventura Souza. Para um novo senso comum: a ciência, o direito e a política na transição paradigmática. 2. ed. São Paulo: Cortez, 2008. v. 4.

SOUZA JR., José Geraldo de Souza (Org.). Educando para os direitos humanos. Porto Alegre: Síntese, 2004.

VIVARTA, Veet (Coord.). Diversidade: mídia e deficiência. Brasília: ANDI; Fundação Banco do Brasil, 2003. 
Univ. Arquitetura e Comunic. Social, Brasília, v. 6, n. 1/2, p. 93-111 , jan./dez. 2009

Inclusão - Revista da Educação Especial: um instrumento de comunicação ...

WERNECK, Claudia. Sociedade inclusiva: quem cabe no seu todos? Rio de Janeiro: WVA, 2002.

ZÉMOR, Pierre. La comunication publique. Paris: PUF, 1995. Tradução resumida do livro pela professora doutora Elizabeth Brandão. Disponível em: <www.ucb.br/ comsocial/mba/ComunicacaoPublicaPierreZemor_traducao.pdf.> Acesso em: 28 mar. 2009. 
